\title{
The Paris Agreement Revisited: Diplomatic Triumphalism or Denial of Climate Justice?
}

\author{
Chrislain Eric Kenfack \\ Department of Political Science, University of Alberta, Edmonton, Alberta, Canada \\ Email:kenfack@ualberta.ca
}

How to cite this paper: Kenfack, C.E. (2022) The Paris Agreement Revisited: Diplomatic Triumphalism or Denial of Climate Justice? Journal of Environmental Protection, 13, 183-203.

https://doi.org/10.4236/jep.2022.132012

Received: December 9, 2021

Accepted: February 6, 2022

Published: February 9, 2022

Copyright () 2022 by author(s) and Scientific Research Publishing Inc. This work is licensed under the Creative Commons Attribution International License (CC BY 4.0).

http://creativecommons.org/licenses/by/4.0/

(c) (i) Open Access

\begin{abstract}
The 2015 Paris COP 21, after the failure of the 2009 Copenhagen COP, raised many expectations regarding the elaboration of the post-Kyoto legal instrument to lead the global fight against climate change. At the sunset of the summit, world leaders and climate negotiators, relayed by mainstream Medias, presented the results of the Paris climate discussions as an important success for the global climate community. A success contested by climate justice and just transition defenders. Given the foundation role the Paris agreement plays for subsequent global, national and sub-national climate policies on one side and, on the other side, the continuous growing global demands for climate justice and just transition, this article investigates the conciliatory possibilities put in place by the agreement to advance those demands. To reach such goals, the article focuses on the retrospective critical reading of the agreement in the light of human-centered climate perspectives such as climate justice and just transition, without neglecting other aspects related to the very nature of the agreement, and the enhanced commodification of nature and resulting carbon trading. This analysis of the agreement through climate justice lenses will be instrumental in confirming or disproving the following hypothesis: From the climate justice and just transition perspectives, the success of the Paris regime will not pass through the implementation of the Paris agreement itself, but thought corrective mechanisms that could be put in place to correct the loopholes of the agreement. The initiative of putting such post-Paris corrective mechanisms in place is expected to be one of the key priorities of the international community.
\end{abstract}

\section{Keywords}

Climate Justice, Climate Politics, Just Transition, Loss and Damage, Paris Agreement 


\section{Introduction: Paris Agreement, an Undisputable Diplomatic Success}

From November $30^{\text {th }}$ to December $12^{\text {th }} 2015$, world leaders and countries delegations gathered in Paris, France, for the 21st session of the conference of the parties to the UNFCCC. Following the drastic failure of the 2009 conference in Copenhagen, and the 2011 conference in Durban that mandated the COP 21 to put in place a legal binding post-Kyoto instrument to fight global warming, negotiators of the Paris conference had the mission of putting such instrument in place. As such, initially expected to end on the 11th, the conference finally took an additional day in order to give negotiators the possibility of agreeing on the last details of the agreement before presenting it to the world.

Made of a preamble of 140 points going from page 1 to 19 , and an operational part containing 29 articles and going from page 20 to 31, the document was unanimously accepted by all COP 21 negotiators, after a thorough discussion on its content and a meticulous choice of terms to be included. According to article 20 paragraph 1, the "agreement shall be open for signature and subject to ratification, acceptance or approval by States and regional economic integration organizations that are parties to the convention. It shall be open for signature at the United Nations Headquarters in New York from 22 April 2016 to 21 April 2017 "'. The agreement, due to enter into force in 2020 [1], aims at "enhancing the implementation of the convention, including its objective to strengthen the global response to the threat of climate change" ([2], Article 2).

Through this long-awaited instrument, the international community intends to pursue its goal of limiting global GHG emissions to a level that can help avoid global climate catastrophe and not reach the point of no-return. It equally intends to put in place policies and mechanisms to better cope with the current adverse effects of climate change, and to address the question of climate finance, loss and damage and the global climate governance architecture among others. Such instrument was qualified as a great success by political leaders and mainstream Medias. In fact, as the then French President Francois Hollande summed it up: "In Paris, there have been many revolutions over the centuries. Today it is the most beautiful and the most peaceful revolution that has just been accomplished-a revolution for climate change" ([3], p. 1). Those claiming the success of the Paris climate event focused on the fact that it was the first global climate treaty to be accepted unanimously by all parties. In other words, the "Paris ${ }^{1}$ During the official ceremony to open the agreement for signature at the Headquarters of the UN in New York, 175 parties signed it, and 15 States deposited their instrument of ratification. Of the 175 parties, there were 174 countries and the European Union (only Regional Organization of Economic integration party to the UNFCCC). One year later, by the end of 2016, 197 parties had signed the agreement. Of the 197 parties, 136 have already deposited their instruments of ratification. The "agreement entered into force on 4 November 2016, thirty days after the date on which at least 55 Parties to the convention accounting in total for at least an estimated $55 \%$ of the total global greenhouse gas emissions have deposited their instruments of ratification, acceptance, approval or accession with the Depositary." (UNFCCC, 2016). As of January 2022, 193 Parties out of 197 Parties to the UNFCCC have ratified the agreement (more details at

https://cop23.unfccc.int/process/the-paris-agreement/status-of-ratification). 
agreement was hailed worldwide as amongst the most significant developments of the history of the global response to climate change" ([4], p. 1). However, on their own side, climate justice defenders view the same summit and the resulting agreement as a failure from an environmental perspective, and a catastrophe for climate justice and just transition. And, five years after its adoption, the agreement continues to be considered a climate justice failure and calls to go beyond Paris continue to flourish [5] [6] [7] [8]. It is on the basis such a contested global climate instrument that the international fight against climate change is currently standing, will continue to be developed and implemented in the coming years and possibly decades. Therefore, taking into consideration such importance of the Paris agreement for the future of climate governance, this article aims at analyzing its content from an anthropo-centered perspective, with a focus on climate justice and just transition (JT). The objective of such analysis, it should be noted, is to determine the loopholes of the current global climate governance architecture. Knowing those loopholes is instrumental in understanding the growing contestation of the global climate governance system by climate justice activists and youths around the world, and in exploring alternatives to that contested system. In order to reach its objective, this article intends to address the following question: Faced with growing calls for climate justice and JT around the world, how did negotiators of the Paris agreement integrate issues of justice in their final deal? To answer that question, this article proceeds through a critical reading of the agreement in the light of evaluation indicators such as climate justice and Just Transition, without neglecting other aspects related to the very nature of the agreement, and the enhanced commodification of nature and its resulting carbon trading.

A closer look at the agreement tends to expose a number of loopholes. For example, one of the most important contradictions is the $1.5^{\circ} \mathrm{C}$ target set by the agreement. Even though this goal was set, the agreement does not actually design a pathway on how to achieve it. Instead, that goal is in direct contradiction with the countries' Intended Nationally Determined Contributions (INDC) ${ }^{2}$ previously submitted to the secretariat of the COP, and which were conceived to be a key element to consider in building the architecture of the COP 21 treaty. In fact, "while more than 150 INDCs from 180 countries, accounting for more than 90 percent of global emissions, have been submitted, current pledges and INDCs are estimated to contain warming only to $2.4^{\circ} \mathrm{C}$ or $2.7^{\circ} \mathrm{C} "$ ([9], p. 3). From a similar perspective, the European Trade Union Confederation (ETUC) affirms that:

There is a worrying gap between the collective ambitions on the one hand, and the aggregate effect of the individual contributions on the other. As-

${ }^{2}$ In preparation of the Paris COP 21 , countries agreed to clearly outline and render public what post-2020 climate actions they intend to take under a new international agreement. These contributions were determined by each country, taking into consideration its national priorities, circumstances and capabilities, and were submitted to the secretariat of the UNFCCC prior to the beginning of the COP 21. 
cribing to the world a collective objective of keeping global warming below $1.5^{\circ} \mathrm{C}$ does not make sense if the individual contributions lead us to $3^{\circ} \mathrm{C}$.

Bridging this gap must be an absolute priority for countries in the coming years, notably by tackling emissions sources which are not covered by the

Paris agreement, like those coming from international transport [10].

Equally, the agreement "did not deliver the specific rules that will govern the monitoring, reporting and verification of emissions and national implementation of those pledges and policies" ([11], p. 21). As such, by failing to put in place clear pathways to achieve tangible results, Paris ended up putting forward more empty promises and false solutions [12]. In other words, the agreement does not state that "here is the current rate of global emissions, here is the rate at which each country is generating emissions, here is a distribution of legally binding definite sums of emissions for each country which will ensure that emissions do not exceed a threshold, and which will guarantee that emissions actually reduce" ([13], p. 944). Going from this same critical perspective, and to better unveil the loopholes of the Paris agreement, this article, using the critical analysis method, will approach the agreement from four fundamental angles: Its contestable legal nature, its relation to market-based mechanisms, its views with regard to climate justice and its vision of JT.

\section{Methodological Considerations}

This paper, presented in the form of a narrative article, uses the critical analysis methodology approach to evaluate the Paris agreement corpus. The critical reading approach I use primarily explores uses of climate justice, just transition and human right-related concepts in the agreement. The statistical approach explores the recurrence in the use of those concepts in the text. In other words, I first explore the text to see if those concepts or other related concepts are used, then I see how many times they are used. This comes from the belief that the number of appearances, to an extent, reveals the importance given to those concepts and realities by authors of the agreement. The main source of this article is the Paris agreement. Secondary sources deriving from scientific and grey literature are used as supplements to support the critical analysis of the main source. Taking into account the critiques addressed to the narrative approach in relation its "desire to interpret across personal accounts in order to investigate and represent the storylines and broader societal narratives which informed them" ([14], p. 2) and, fully aware of the critiques that can be addressed to my methodological approach in terms of limited objectivity [15], I back my position up with standpoint and strong objectivity approaches. In this respect, it is important to clarify that I do not understand objectivity in the sense of neutrality. Beside being practically impossible, the neutrality ideal provides no resistance to the production of systematically distorted results of research [16]. Moreover, "the conventional notion of objectivity that links it to the neutrality ideal appears too weak to do what it sets out to do" ([17], p. 346). Based on the conviction that 
the personal implication and experience of the researcher can provide him with essential information on how the object of study functions [15] [18], I consider objectivity not in the sense of neutrality, but of detachment, distanciation and self-criticism of my own subjectivity. In the methodological approach that I adopt, the social location of the researcher is therefore closely linked to the epistemic position that leads his analysis. This is particularly important because, in the research context where the position of the marginalized offers possibilities for a strong objective science, social locations, also understood in the sense of social status, offer the potential to be more epistemically reliable than others [19]. Such social status, as Harding [16] argues, offers an incredibly effective opportunity for production of sound knowledge about marginalized groups. In the context of this article, the socio-epistemic position I take to analyze the Paris agreement, is that of climate justice and JT defenders, those marginalized who have been put at the periphery of climate decision-making processes.

\section{Paris Agreement: Legal Considerations}

One of the main points we can question about the Paris agreement is its very nature. The question here is to know if the agreement, as expected, is legally binding or not. This question is complicated to address, as points of view are divergent depending on whether analysts support the agreement or not. According to the European Commission, "at the Paris climate conference (COP21) in December 2015, 195 countries adopted the first-ever universal, legally binding global climate deal" [1]. This was in fulfillment of the engagement parties took in 2011 in Durban, "to launch a process to develop a protocol, another legal instrument or an agreed outcome with legal force under the convention applicable to all parties" ([20], Article 1). The originality of the Paris agreement, according to some authors, is that it adopts an innovative legal approach that does not require the vote of the American Senate to be ratified by the USA which was the main opponent to the Paris outcome being legally binding [21] [22]. From this perspective, even though the agreement cannot be aligned to traditional treaty-types like the Kyoto Protocol, its reliance on the convention gives it a legal character. Relying on the understanding of a treaty as defined by the international law, the authors clarify their position in the following words:

In public international law, a treaty is defined as meaning "an international agreement concluded between States in written form and governed by international law". The Paris Agreement was certainly concluded between states and in written form, but is it also governed by international law? Since the agreement was concluded at an international conference "in pursuit of the objectives of the Convention" and since it uses the bodies and procedures developed in the context of the Convention (undoubtedly an international treaty) it may safely be concluded that it is governed by international law. The Paris Agreement is thus a (dependent) treaty under international law. It is dependent on the UNFCCC because only Parties to the 
Convention may ratify and because it cannot stand alone since many clauses refer to the respective procedures and bodies of the UNFCCC ([21], p. 13).

Nevertheless, if for those authors there is no doubt about the legal binding nature of the accord, others are more tempered in their position and prefer to speak of the Paris agreement as one having both binding and non-binding provisions. For example, for Jones Day ([9], p. 3), "the binding provisions are mostly procedural and include commitments to 1) submit an INDC, 2) submit an updated INDC every five years, 3) demonstrate a progression in subsequent INDCs, 4) pursue domestic measures to achieve INDCs, and 5) submit emissions inventories and information necessary to achieve INDCs." Considered from this perspective, the full legal nature of the agreement can seriously be questioned. Was the purpose of the agreement to put in place procedures to be followed, or to build adaptation, mitigation, finance, loss and damage mechanisms that could slow down climate change at the global level, while enhancing the resilience capacities of world ecosystems, biodiversity and populations under changing climate? Considered from this second perspective, the non-binding nature of the agreement can easily be pointed out. In fact, even though the Paris agreement deals with all the important above-mentioned aspects of the global fight against climate change, from the legal binding perspective it is a "potentially weak and essentially voluntary agreement" ([13], p. 945). In other words, "there are no means for enforcement. Article 15 on implementation and compliance establishes an expert committee that will be 'non-adversarial and non-punitive', which means that it has no teeth and can do nothing about non-compliance" ([23], p. 930). To confirm this point, we can report to the following illustrative anecdote concerning the use of the word "shall" or "should" in the final version of the agreement:

US lawyers detected a (legally binding) "shall” instead of a (entirely voluntary) "should" in the Article 4.4 referring to developed countries taking the lead in economy-wide emission reduction targets. The reinsertion of the convention wording "should" delayed the closing plenary by several hours. It was communicated to the closing plenary as a technical/translation error due to late night working hours [24].

This apparently anecdotic fact demonstrates how the US delegation did everything within their reach to avoid granting to the text any legal force which, in return, would have forced the American administration to require the vote of the senate before ratifying it. Taking this anecdotic fact, I thus argue that, since nobody reacted to the supremacy of the US in this matter, the final text was adopted with no legal binding force and the operationalization of fighting mechanisms was left to countries. This then left to countries the uncontested power to freely decide on their level of contribution to global emissions reduction, according to their national contexts, capacities and political will, without any in- 
ternationally set emissions target, as it was the case under the Kyoto protocol, nor any legally binding enforcement mechanism. So, in order to secure the adherence of the US, and of the greatest numbers of parties to the United Nations Framework Convention on Climate Change (UNFCCC), negotiators proceeded by "abandoning attempts to create a legally binding system, and instead adopting the voluntary Paris agreement" ([7], p. 84). Having succeeded to "force" the other parties to the negotiations to strip the agreement from such legal binding disposition the US signed the agreement; a signature that will be revoked less than two years later by president Trump. The election of Joe Biden raised a wave of hope among defenders of the climate cause [25], as he decided to rejoin the agreement. Moreover, upon rejoining the Paris agreement, Biden's administration "submitted a relatively ambitious NDC [National Determined Contribution] promising a 50\% - 52\% reduction in greenhouse gas emissions by 2030 from a 2005 baseline, alongside goals to create a 'carbon pollution-free power sector by 2025 ' and 'net greenhouse gas emission economy by no later than 2050"' ([7], pp. 88-89). However I argue, in this article, that even though Joe Biden rejoining the Paris agreement is a success story for climate diplomacy, it is not necessary a good new for climate justice or JT, since the agreement does not put in place mechanisms to secure climate justice and JT. Moreover, this signing-withdrawal-resigning cycle of global climate agreements is not new in the recent history of global climate governance. In 2001, under the leadership of president George W. Bush, the US withdrew from the Kyoto protocol that was signed under president Bill Clinton on November 12, 1998 [26]. In April 2016, the US signed the Paris agreement under the leadership of president Barrack Obama, and on June 1, 2017, president Donald Trump officially took a stand that the US will be withdrawing from the Paris agreement. A formal notice of withdrawal was served to the UN Secretariat by the US administration on November 4, 2019, and took effect on November 4, 2020, in accordance with article 28 of the Paris agreement, that stipulates that parties can only withdraw after three years, and their withdrawal takes effect 12 month after they have notified the UN secretariat. Therefore, "the Paris Agreement is the second global climate change pact that the United States joined under a Democrat and abandoned under a Republican" [27]. Taking into consideration the fact that the Paris Agreement, together with the Kyoto protocol are the only two reinforcing additional global agreement under the UNFCCC, we can therefore state that the US has never given a great importance to global climate agreements for a substantial amount of time. As Beggin Riley [26] reports, "Bush, like Trump, was also a climate change skeptic", and president Bush, during his 2000 presidential campaign, stated: "The Kyoto Treaty would affect our economy in a negative way," and "we do not know how much our climate could or will change in the future. We do not know how fast change will occur, or even how some of our actions could impact it". Just to say, beside their shared climate sceptic inclinations, both presidents Bush and Trump, on withdrawing the US from the global cli- 
mate agreements, based their arguments on the protection of the US economy and the desire to avoid the rise of energy prices [26]. From those above observations, I argue that what is at stake here is not the urgent need to address global climate change and the resulting need for climate justice, JT and just recovery. What is important is the preservation and protection of the US economy.

On the other side, it should be stressed, the very Paris agreement does not put in place any guarantee to substantially reduce global emissions [28]. Relying on such instrument to keep global temperatures under $2^{\circ} \mathrm{C}$, and preferably $1.5^{\circ} \mathrm{C}$ as the agreement states, becomes really problematic and, to an extent, a simple utopia for two reasons: 1) The aggregate of all the INDCs submitted by parties, and on which the agreement lies, goes far beyond the 2 degrees $\mathrm{C}$ target. Instead, it puts us on "track for a world that is 2.7 - 3.7 degrees C warmer (median chance), depending on modeling assumptions" [29]. 2) As Gudynas observes, there is often a certain decoupling between parties' international commitments and their national policies and strategies. To clarify this point, he goes from the contradictions between Bolivia's international discourses and pledges for the protection of the right of Mother Earth, and its national

Ineffective environmental policies, weak enforcement, lack of political leadership, and the disinterest of urban majorities toward the ecological situation in remote corners of the country [...], [we can conclude that] Agreements like the one reached in Paris are still very weak to solve this decoupling, because it rests on voluntary measures at the national level, and does not impose fundamental questioning on the core ideas of development ([30], p. 939).

In other words, even when countries take commitments at the international level, there is no guarantee that they will implement them at the national level. The example of the Kyoto protocol is quite illustrative at this point. Such legal binding global climate instrument did not help to reduce global GHG emissions. Instead, during its implementation period, the world witnessed an increase in global emissions. In this regard, data provided by the German Federal Ministry of Environment, Nature conservation, Building and Nuclear Security [31] show that, despite the market-oriented mechanisms and legally binding safeguards put in place under the Kyoto protocol, global GHG emissions, by 2010, had risen by around 29\% compared to the 1990 levels during the first commitment period of the protocol (2008-2012). The 2015 data show an average rise of $2.5 \%$, implying an increase of 65\% above 1990 levels because of the economic growth in both China and India [32]. Based on that, I argue that, if under the Kyoto protocol that was legally binding, we witnessed an increase of global GHG instead of the intended reduction, we can logically expect that, under the Paris agreement, which is not legally binding, we might witness even greater emissions levels. This argument is reinforced by other researchers who equally argue that, apart from the temporary decline in greenhouse gas emissions due to the global economic fallout caused by the COVID-19 pandemic, emissions continue to increase glo- 
bally, with carbon dioxide concentrations reaching 420 parts per million (ppm) in 2020, in contrast to the pre-industrial level of $280 \mathrm{ppm}$ [6] [33] [34]. Based on those observations I argue in this article that, from its very nature and from its very beginning, the Paris agreement was designed to fail from a climate perspective, unless corrective decisions are taken and corrective measures are put in place during its implementation phase.

\section{Carbon Trading: Nature on the Shelves}

One of the important innovations of the Kyoto protocol was the consecration of international market-based mechanisms as dominant approaches in fighting global warming. Those mechanisms, also known as flexible mechanisms, were three in the protocol and later saw the development of another mechanism that, even though not integrated in the protocol, became widely implemented and integrated within the UNFCCC habits and vocabulary, and known as REDD. As such, until now the global fight against climate change was dominated by four market-oriented mechanisms that have all proven to be ineffective in properly tackling global warming at the global level. The Paris agreement was therefore expected to put in place mechanisms other than the market that could help fight global warming. Obviously, the expression non-market approaches appears five times in the agreement and parties are encouraged to strive to use them. On the contrary, the agreement acknowledges that markets are needed to get countries on a low emissions development pathway and enhance ambition to keep warming to well below $2^{\circ} \mathrm{C}$, by clearly recognizing the importance of tools such as carbon pricing. By so doing, it continues to channel global emissions reduction initiatives towards the market as initiated by the Kyoto protocol. According to Eva Filzmoser, director at Carbon Market Watch, in a press statement following the closing of the COP 21 ,

The Paris agreement contains several provisions related to carbon pricing and markets. Countries can use and transfer "mitigation outcomes" to other countries, which opens the door to the linking of Emissions Trading Systems. The accounting rules for such transfers will be developed in the coming years and will include guidance on how to avoid the "hot air" trading of bogus pollution permits, including the avoidance of doubled-counted emission reductions. The agreement also obliges countries to promote environmental integrity and to pursue domestic climate measures to achieve their targets, thereby limiting the amount of international carbon credits that can be used ${ }^{3}$.

For those who were expecting COP 21 to put an end to the global market-oriented climate regime, the Paris agreement came as a great disappointment. In fact, not only it did not consecrate the end of carbon trading, it instead re-affirmed it, and went further by laying the groundwork for a new mar- 
ket-based mechanism by establishing "a new mechanism to succeed the Kyoto Protocol's Clean Development Mechanism, which generates tradable emission offsets. Rules for the new mechanism are to be adopted at the first meeting of parties after the agreement takes force" ([3], p. 3). As the Centre for Climate and Energy Solution continues developing its argument, even though the agreement did all the necessary efforts to avoid any direct reference to the use of the word "market" and "Kyoto Units" (except when it had to talk of non-market based approaches), it nevertheless recognized that parties may use ITMOs to implement their INDCs, on a voluntary basis. Equally, as Fuhr et al. pointed out, the agreement used several other concepts that refer indirectly to market-based approaches as a way forward; According to their analysis of the text:

The concept of market-based approaches is anchored in the form of multiple synonyms found throughout the entire text. Expressions such as "cooperative approaches", "internationally transferred mitigation outcomes", "enhanced" this and that-appearing no less than 50 times throughout the Paris agreement-all refer implicitly to market approaches. Another euphemism liberally used to convey the idea of markets without mentioning them outright is the word "opportunity/ies" which appears around 13 times, making it clear from its contextual placement that the Paris agreement creates a big opening for companies to come in [24].

With that implicit recognition in general, and the encouragement to use the ITMOs in particular, the agreement created a new class of carbon assets and put forward the idea of a new mechanism that will help create and monetize the next generation of carbon credits, including those achieved through policy action [35]. With such continuous focus on the market to solve the climate crisis, the agreement gives little importance to matters related to human rights in general and climate justice in particular.

\section{Climate Justice in the Agreement}

In the preamble on the agreement we can read the following statement:

The Parties to this agreement [...] Noting the importance of ensuring the integrity of all ecosystems, including oceans, and the protection of biodiversity, recognized by some cultures as Mother Earth, and noting the importance for some of the concept of "climate justice", when taking action to address climate change [...] Have agreed [to put in place the operational part of the Paris agreement] ([2], Article 20).

This is the only paragraph that clearly mentions the concept of climate justice in the agreement. Nevertheless, beside that, another expression such as "public participation and public access to information", which to an extent refers to one dimension of justice (mostly the participatory dimension), is used three times in the text. Of the three times, two are in the preamble and one in article 2. Another statement that reminds of the idea of justice in the agreement is the acknowl- 
edgement of the importance of human rights in the following terms:

Acknowledging that climate change is a common concern of humankind, Parties should, when taking action to address climate change, respect, promote and consider their respective obligations on human rights, the right to health, the rights of indigenous peoples, local communities, migrants, children, persons with disabilities and people in vulnerable situations and the right to development, as well as gender equality, empowerment of women and intergenerational equity ([2], Article 1) ([2], Article 20).

When considered closely, each use of these categories related to climate justice and human rights has no legal force in the agreement. First of all, the agreement only takes note of the importance of climate justice, and it is necessary to underline that the mentioning of climate justice in the text is preceded by the expression importance "for some", meaning that climate justice is not a general matter and should not be considered as such when taking climate initiatives. Climate justice, in this context, is a matter concerning a category of people whose voice can be heard, or ignored, like that of any group when considering climate change. Such restrictive way of qualifying climate justice has huge political and legal implications. Climate change, from the human and social point of view, is basically a problem of justice: justice for nature through the sustainable use of natural resources, and justice for all humans in the management of global warming. That is why climate justice cannot be considered as a matter only for some people. In this regards, "we need to [...] open our eyes to how countless 'others' have suffered the true costs of the global ecological crisis, and struggled for survival" ([36], p. 146). By not complying with the principles of climate justice, there is a great risk that the global fight against climate change will not go the right way. Also, when talking of public participation in climate decision-making processes, three elements are worth mentioning. In its first usage of the concept, the agreement only invites the COP to explore ways of enhancing it, while in the second usage it only affirms the importance of public participation. The third and last usage appears in Article 2 of the agreement as a call and as an encouragement to the parties involved. In other words, the agreement does not do justice to non-state and non-sovereign actors by enhancing measures to secure their full participation to decision-making processes. Instead, it leaves everything to neoliberal state actors struggling to secure their self-absorbed interests as well as those of polluting corporations. Based on that, Victor Menotti from the International Forum on Globalization, reacting after the release of the agreement, concluded that 'the Paris agreement will be known as the Polluters' Great Escape since it weakens rules on the rich countries and puts the world on a pathway to $3^{\circ} \mathrm{C}$ warming" ${ }^{\prime 4}$. Going in the same line Nick Dearden, the director of Global Justice Now declared in a press release immediately after the closing of COP 21:

${ }^{4}$ For further details, refer to

http://oneworld.org/2015/12/12/too-weak-too-late-says-climate-justice-campaigners/. 
The Paris negotiators are caught up in a frenzy of self-congratulation about 1.5 degrees being included in the agreement, but the reality is that the reductions on the table are still locking us into 3 degrees of global warming. This will have catastrophic impacts on some of the most vulnerable countries and communities. And yet the deal seems to be shifting more responsibility on those countries who are least responsible for the problem, and the finance that has been agreed on is just a fraction of what is broadly agreed is necessary for those countries to cope with the impacts of climate catastrophe. The bullying and arm twisting of rich countries, combined with the pressure to agree to a deal at all costs, has ensured that the agreement will prevent poor countries from seeking redress for the devastating impacts of a crisis that has been thrust upon them [37].

Such shift of responsibility, endorsed by the Paris agreement, consecrated a new form of global climate injustice, an injustice conventionally built within the UNFCCC and that will be the foundation of global climate politics in the upcoming years.

The second perspective that reveals the unjust nature of the agreement is its disguised institutionalization of climate injustice through the non-liability with regard to loss and damage. In fact, discussions on the loss and damage mechanism started becoming important within the UNFCCC in 2010 COP 16 in Cancun. Negotiations initiated in Cancun led to the establishment of the International Mechanism for loss and damage at the Warsaw COP 19 in 2013, and an executive committee was put in place to further develop and ensure its implementation [38]. Even though the emergence of the debate is quite recent, some authors trace the origin of the loss and damage back to 1991, when the group of Small Island States started calling for the establishment of an international insurance mechanism to compensate the victims of sea level rise [38] [39] [40]. It should be recalled that the notion of loss and damage refers to the adverse effects of climate change that surpass people's adaptive capacity with regard to global warming impacts [41] [42]. The loss and damage impacts may among others be related to weather-related natural hazards, sea-level rise; increasing temperatures; ocean acidification; glacial retreat and related impacts; salinization; land and forest degradation; loss of biodiversity; and desertification [20] [42]. This mechanism is the third pillar, beside adaptation and mitigation that the international community has put in place to fight against global warming [43]. In other words, since the mitigation mechanism addresses the root-cause of climate change by focusing on the reduction of GHG emissions, and adaptation deals with mechanisms that can reduce the impacts of already occurred changes on nature, economies and humans among others, loss and damage is transversal to both and is concerned with learning to live with the irreversible effects of global warming. The Paris deal is the first international agreement to officially integrate loss and damage as a stand-alone mechanism to tackle climate change [38], even though such "recognition of loss and damage as a part of the Paris agreement on 
the one hand and the exclusion of liability and compensation on the other were the crunch issues that dominated the negotiations on this issue from the very beginning" ([21], p. 27).

In fact, the agreement integrates the loss and damage resulting from anthropogenic emissions (mostly from developed countries) but immediately excludes the liability and compensation based on that recognition for countries that participated the least to the crisis and that are most exposed to loss and damage. Taking into consideration such contradictory situation, I argue that loss and damage, as considered by the Paris agreement, cannot be seen as a success from a climate justice perspective. In fact, the introduction of the very concept of loss and damage in the climate deal reminds us of the responsibility of polluters, while the evocation of non-liability renders them irresponsive of their actions. Simply put, it goes thus: We acknowledge that global warming causes loss and damage to humanity, and we recognize that fossil companies and rich countries are historically responsible of global warming, and are still not ready to divest from fossil fuel. However, we do not want their responsibility to be engaged in attempting to resolve the crisis. That is why, from my perspective, I conceive loss and damage as a disguised acknowledgement of the failure of global climate diplomacy, and the inclusion of non-liability and non-compensation in the agreement as an institutionalization of global climate injustice within the UNFCCC.

\section{Just Transition (JT): A Simulated Presence}

One of the most important expectations was that the Paris agreement should definitely turn the page of fossil fuel and engage the international community on the path to renewable energies and JT to low carbon economy. The concept of JT appears only once in the agreement, in the following statement of the preamble: "The Parties to this agreement [...] taking into account the imperatives of a Just Transition of the workforce and the creation of decent work and quality jobs in accordance with nationally defined development priorities [...] have agreed [to put in place the operational part of the Paris agreement]." The limited importance of the concept of JT, as well as that of respect for human rights in the rest of the text, results from the fact that too many governments refused to commit to them in the operational sections of the agreement [44]. Nevertheless, despite such reluctance of governments and especially their refusal to mention them in the operational part of the agreement, some people see the only mention done in the preamble as a proof of engagement in the path of JT. According to the International Labour Organization (ILO) for example, in its post-COP 21 declaration, the agreement highlights in particular "the imperative of a Just Transition of the workforce and the creation of decent work and quality jobs in accordance with nationally defined development priorities" [45]. The ILO continues its argument by quoting its General Director, Guy Ryder, who gives more weight to that official position by declaring: "The world has come a long way in realizing 
that acting on climate change and promoting job creation and social inclusion are intertwined challenges of the 21st century, and ones that we must confront together if we are to realize the aspirations of social justice" [45]. At this level, it is important to consider the declarations of the UN Agency and the UN diplomat from a critical perspective. First, the paragraph of the agreement on which they ground their arguments is just a statement made by negotiators and found in the preamble. Secondly, the operational part of the agreement does not make any reference to JT and no directives are given concerning the implementation of such transition, the respect of human rights in general and workers' rights in particular. That is why Teresa Anderson, Policy Officer at ActionAid International concludes:

The deal fails to deliver the rules and tools to ensure that climate change doesn't spiral out of control. Many in Paris seem to have forgotten the very people that this climate agreement was supposed to protect. The deal won't deliver support to help farmers in developing countries whose crops are failing as a result to climate impacts. It does not ensure that food security is protected, and it could even drive farmers off their land, by allowing dubious climate offsetting strategies $[46]^{5}$.

As Anderson says, the Paris deal was not a particularly good news for Global South farmers. By failing to ensure that the deal will guarantee an appropriate reduction in global GHG and lead to the stabilization of global climate, negotiators contributed to condemn Global South peasants whose agricultural activities and productivity mostly rely on rain-fed systems, and therefore very vulnerable when there are variabilities in precipitation patterns. For example, "climate change is expected to impact crop production in Africa through changes in temperature and the quantity and temporal distribution of water supply" [47], and the reduction of cultivable areas due to the destruction of ecosystems and the rise in sea level [48] [49]. Moreover, the Paris agreement failed to mention agriculture, or to put in place mechanisms to ensure safe and productive farming. Such omission by the agreement is surprising, given that Article 4.1(e) of the Convention explicitly calls all parties to cooperate to "develop and elaborate appropriate and integrated plans for coastal zone management, water resources and agriculture and for the protection and rehabilitation of areas, particularly in Africa, affected by drought and desertification, as well as floods" [50]. I therefore argue that such omission is not only a threat to agriculture practices and productivity, it is also a threat to peasant's means of substance and survival, and a threat to their basic human right to a safe environment as defined by the first principle of the Stockholm Declaration [51].

Equally, ETUC goes in the same line in its post-Paris statement in the following words:

${ }^{5}$ For further details, refer to:

http://oneworld.org/2015/12/12/too-weak-too-late-says-climate-justice-campaigners/. 
The Paris agreement has failed to secure a clear commitment from the Parties that they will design and implement their climate policies with full respect for human rights and promoting a just transition for the workforce as well as decent and quality jobs. The reference inter alia to human rights, to gender equality, to intergenerational equity, and to just transition and decent work in the preamble of the text is indeed a significant acknowledgment of the importance of these principles in the context of climate action, but is not enough to ensure the wide public support that long term climate action will require. Tackling climate change requires a change of society, and this must be done in cooperation with people, not at the expense of their rights [10].

Finally, instead of officially consecrating the end of fossil fuel, the Paris agreement gives a great importance to techno-fixes as suitable solutions. For example, the terms technology/technological appear 63 times in the agreement, both in the preamble and in the operational part of the text. The multiple and repetitive use of those concepts, to an extent, demonstrates the importance given to techno-fixes by negotiators of the agreement. Furthermore, Article 10 clearly points out the importance of technology for the implementation of mitigation and adaptation actions, and establishes a technological framework to provide overarching guidance for the work of the Technology Mechanism of the convention. By providing this opening, the convention gives more flexibility both to the private and public sector to reply and invest in techno-fixes mechanisms as solutions to climate change [52]. This optimism and the importance given to techno-science appears to be the only option the agreement gives since, as Gigounas et al. rightly conclude:

The agreement creates no direct restrictions on the extraction, release, or use of fossil fuels. Even in countries where the agreement would automatically constitute a source of national law, the provisions are not drafted to create direct obligations on energy companies or to impose liability for fossil fuel-based energy operation. Conversely, the agreement allows legislators to decide how to achieve its fundamental aims. The approaches parties may take are therefore unpredictable, and the energy industry would need to observe policy changes closely to prepare for new legislative regimes [52].

The importance attached to techno-fixes demonstrates the reluctance of the international community in fully engaging itself in the path of transition to a low carbon economy. Instead, false solutions continue to be put forward. The insistence on techno-fixes is problematic for three main reasons: First, it opens the road for corporates' investments in the development of hypothetical techniques and technologies to keep on patching the wounds created by global warming rather than looking for long-lasting solutions. In other words technological solutions such as geoengineering or carbon capture and storage among others, are "primarily concerned with maintaining business as usual regardless of hu- 
man-induced climate change or any other environmental problem" ([23], p. 929). Secondly, the carbon capture and storage and other technological solutions are still largely underdeveloped and untested [13] [53]. Thus, relying on such approaches implies that the already deteriorating nature will be used as a testing ground, with the possibility of creating other irreversible dangerous scenarios. Third, in encouraging techno-fixes solutions, global leaders did not consider the transversal negative effects they could have on other sectors. Here, we can consider the negative effects that massive investments in negative emissions technologies such as the "Bio-Energy with Carbon Capture and Storage (BECCS), an expansion of trees and crops that extract carbon dioxide alongside the injection of carbon dioxide into geological formations" ([53], p. 3), will have on agriculture and food security. Such technology requires the use of large surfaces, and the lands to be used will either be grabbed from local communities and individuals, or obtained after deforestation or degradation of forest areas that are home to many Indigenous Peoples and communities among others, therefore creating situations of more social and climate injustices, and enhanced inequalities. That is why Buxton concludes that the

Determination to constantly look for illusory techno-fixes and sustain capital expansion at all costs, is why despite the "show" at Paris, the real action on climate change is more often to be seen in military and corporate strategies that seek to manage climate change consequences rather than tackle its underlying causes ([53], p. 3).

\section{Conclusions}

From the above analysis, we can draw four fundamental conclusions:

- The Paris agreement, from all indications, was a great and uncontestable success from a diplomatic point of view. In fact, unlike the other previous global agreements, the Paris accord won the adherence of all states present right from the very beginning, and all participating parties signed it.

- The Paris agreement does not put in place any strong mechanism to secure the implementation of climate justice measures. Instead, it restricts its importance to "some", and goes ahead to institutionalize global climate injustice through the proclamation of non-liability with regards to loss and damage.

- The Paris agreement, even though it wishes the advent of JT, does not put in place any mechanism to render such transition possible. As such, our environment, workers, their livelihood and their communities' destinies are still abandoned into the hands of neoliberal capitalists solely motivated by the race for unlimited profits.

- The Paris agreement, following the tradition initiated at the global level by the Kyoto protocol [54], puts in place a mechanism to facilitate the commodification of nature and the resulting carbon trading, instead of creating a pathway for a market-free nature. The Paris-instituted Internationally Transferred Mitigation Outcome (ITMO), coupled to the non-abrogated market 
mechanisms of the Kyoto regime and the largely implemented REDD+ mechanism will continue to introduce nature into the market and create possibilities of shifted GHG emissions rather than properly cutting them down.

The above conclusions, as I have argued in this article, simply reveal one thing: By failing to comply with fundamental dimensions of climate justice and JT the Paris agreement portrays an image of a simple instrument used by the neoliberal capitalist system to further commodify and marketize nature, rather than solving the climate crisis. Such failure of the agreement is a call to reflect on this 2019 declaration of Greta Thunberg accusing world leaders engaged in climate fight in the following term: "We are in the beginning of a mass extension and all you can speak about is money and fairytales of eternal economic growth. How dare! [...] How dare you continue to look away, and come here saying that you are doing enough, when the politics and solutions needed are still nowhere in sight" [55]. The Paris agreement omission to open ways to climate justice and JT, and its continuous reliance on the market and techno-fixes approaches is an indication that, as Thunberg [5] again rightly puts it, "we are still in a state of complete denial, as we waste our time, creating new loopholes with empty words and creative accounting". In other words, the future of global climate politics will hold to its integration of principles of climate justice and JT, and a human-centered rather than market and hypothetic techno-fixes orientation, and that is exactly what the Paris agreement failed to do.

\section{Acknowledgements}

This work was generously supported, financially, by the Killam trust, through the Izaak Walton Killam Memorial Postdoctoral Fellowship, at the University of Alberta, and by the Queen Elizabeth Scholars programme through the "ecological economics, commons governance, and climate justice" project at the University of York. Our gratitude equally goes to Pr. Laurie Adkin and Pr. Ellie Perkins for their constant support and mentoring.

\section{Conflicts of Interest}

The author declares no conflicts of interest regarding the publication of this paper.

\section{References}

[1] European Commission (2015) Paris Agreement. https://ec.europa.eu/clima/eu-action/international-action-climate-change/climate-n egotiations/paris-agreement_en

[2] UNFCCC (2015) Adoption of the Paris Agreement. http://unfccc.int/resource/docs/2015/cop21/eng/109r01.pdf

[3] Centre for Climate and Energy Solution (2015) Market Mechanisms: Understanding the Options. https://www.c2es.org/publications/market-mechanisms-understanding-options

[4] Umbers, L. and Moss, J. (2020) Introduction. In: Umbers, L. and Moss, J., Eds., 
Climate Justice and Non-State Actors. Corporations, Regions, Cities, and Individuals, Routledge, Oxon, 1-11. https://doi.org/10.4324/9780429351877-101

[5] Thunberg, G. (2020) We Are Speeding in the Wrong Direction on Climate Crisis. The Guardian.

https://www.theguardian.com/environment/2020/dec/10/greta-thunberg-we-are-sp eeding-in-the-wrong-direction-on-climate-crisis

[6] Harris, P.G. (2021) Reversing the Failures of Climate Governance: Radical Action for Climate Justice. In: Böhm, S. and Sullivan, S., Eds., Negotiating Climate Change in Crisis, Open Book Publishers, Cambridge, 243-252. https://doi.org/10.11647/obp.0265.19

[7] Hannis, M. (2021) We'll Always Have Paris. In: Böhm, S. and Sullivan, S., Eds., Negotiating Climate Change in Crisis, Open Book Publishers, Cambridge, 83-96. https://doi.org/10.11647/obp.0265.07

[8] Nakate, V. (2021) A Rise of 1.2 Degrees Celsius is Already Hell for Me. Vogue, 6 January 2021.

https://www.vogue.com/article/vanessa-nakate-climate-change-activist-how-to-take -action

[9] Day, J. (2015) Paris Agreement Sets the Stage for Global Greenhouse Gas Emission Reductions.

http://www.jonesday.com/files/Publication/4b8db255-4f58-456f-9cba-53c1830587f9 /Presentation/PublicationAttachment/37733814-f7ac-4f2e-9d19-709595c3fec3/Paris \%20Agreement\%20Sets\%20the\%20Stage.pdf

[10] ETUC (2016) ETUC Declaration on the Paris Agreement on Climate Change. https://www.etuc.org/en/document/etuc-declaration-paris-agreement-climate-chan ge

[11] Falkner, R. (2016) The Paris Agreement and the New Logic of International Climate Politics. International Affairs, 92, 1107-1125. https://doi.org/10.1111/1468-2346.12708

[12] Vilela, M. (2015) Climate Justice Groups Respond to the Paris Agreement. http://oneworld.org/2015/12/12/too-weak-too-late-says-climate-justice-campaigners

[13] Morgan, J. (2016) Paris COP 21: Power that Speaks the Truth? Globalizations, 13, 943-951. https://doi.org/10.1080/14747731.2016.1163863

[14] Bell, A. (2003) A Narrative Approach to Research. Canadian Journal of Environmental Education, 8, 95-110.

[15] Leander, A. (2013) "Strong Objectivity" in Security Studies: Ethnographic Contributions to Method Development. Carlos Alberto Notebooks 301. https://www.carloalberto.org/assets/working-papers/no.301.pdf

[16] Harding, S. (1992) After the Neutrality Ideal: Science, Politics, and "Strong Objectivity". Social Research, 50, 567-588.

[17] Harding, S. (1995) "Strong Objectivity": A Response to the Notion of Objectivity Question. Synthese, 104, 331-349. https://doi.org/10.1007/BF01064504

[18] Gobo, G. (2001) Descrivere il Mondo. Carocci, Roma.

[19] Zalta, A.N., Nodelman, U., Allen, C. and Perry, J. (2006) Feminist Social Epistemology. In: Stanford Encyclopedia of Philosophy, The Metaphysics Research Lab, Stanford. http://plato.stanford.edu/entries/feminist-social-epistemology/\#StrObj

[20] UNFCCC (2012) Views and Information from Parties and Relevant Organizations on the Possible Elements to Be Included in the Recommendations on Loss and Damage in Accordance with Decision 1/CP.16. Submissions from Parties and Rele- 
vant Organizations. http://unfccc.int/resource/docs/2012/sbi/eng/misc14a01.pdf

[21] Obergassel, W., Arens, C., Hermwille, L., Kreibich, N., Mersmann, F., Ott, H.E. and Wang-Helmreich, H. (2016) Phoenix from the Ashes-An Analysis of the Paris Agreement to the United Nations Framework Convention on Climate Change. Wuppertal Institute for Climate, Environment and Energy, Wuppertal.

[22] Busby, J. (2016) After Paris: Good Enough Climate Governance. Current History, 19, 3-9. https://doi.org/10.1525/curh.2016.115.777.3

[23] Spash, C.L. (2016) This Changes Nothing: The Paris Agreement to Ignore Reality. Globalizations, 13, 928-933. https://doi.org/10.1080/14747731.2016.1161119

[24] Fuhr, L., Schalatek, L., Primova, R., Verolme, H., Santos, M. and Bogunovic, D. (2015) COP 21 and the Paris Agreement: A Force Awakened. https://us.boell.org/2015/12/15/cop-21-and-paris-agreement-force-awakened https://doi.org/10.1142/S2345748116500093

[25] Kanno-Youngs, Z. and Tankersley, J. (2021) Biden Urges Climate Action: "We Don't Have Much More than 10 Years".

https://www.nytimes.com/2021/09/14/us/politics/biden-climate-change.html

[26] Beggin, R. (2017) The Last Time a US President Dumped a Global Climate Deal: President George W. Bush Was against the Kyoto Protocol.

https://abcnews.go.com/Politics/time-us-president-dumped-global-climate-deal/sto ry?id=47771005

[27] Friedman, L. (2019) Trump Serves Notice to Quit Paris Climate Agreement. https://www.nytimes.com/2019/11/04/climate/trump-paris-agreement-climate.html

[28] Kenfack, C.E. (Forthcoming) Climate Politics from Below. The Climate Jobs Campaign as a Social Movement Response to Global Climate Governance. Engineer Antonio de Almeida Foundation, Porto.

[29] Levin, K. and Fransen, T. (2015) Insider: Why Are INDC Studies Reaching Different Temperature Estimates? World Resources Institute.

http://www.wri.org/blog/2015/11/insider-why-are-indc-studies-reaching-different-t emperature-estimates

[30] Gudynas, E. (2016) Climate Change, the Quadrilemma of Globalization, and Other Politically Incorrect Reactions. Globalizations, 13, 938-942.

https://doi.org/10.1080/14747731.2016.1162995

[31] Federal Ministry of Environment, Nature Conservation, Building and Nuclear Security (2015) Commitment-Periods.

https://www.bmuv.de/en/topics/climate-adaptation/climate-protection/internationa l-climate-policy/kyoto-protocol/commitment-periods

[32] King, E. (2015) Kyoto Protocol: 10 Years of the World's First Climate Change Treaty.

https://www.climatechangenews.com/2015/02/16/kyoto-protocol-10-years-of-the-w orlds-first-climate-change-treaty/

[33] Monroe, R. (2021) Coronavirus Response Barely Slows Rising Carbon Dioxide. Scripps Institution of Oceanography.

https://scripps.ucsd.edu/news/Coronavirus-response-barely-slows-rising-carbon-di oxide

[34] Tan, C.H., Ong, M.Y., Nomanbhay, S.M., Shamsuddin, A.H. and Show, P.L. (2021) The Influence of COVID-19 on Global $\mathrm{CO}_{2}$ Emissions and Climate Change: A Perspective from Malaysia. Sustainability, 13, 1-19. https://doi.org/10.3390/su13158461

[35] Widge, K. (2015) Carbon Markets in the Paris Agreement-An Early Holiday Gift. 
https://blogs.worldbank.org/climatechange/carbon-markets-paris-agreement-earlyholiday-gift

[36] Barca, S. (2016) On the Political in Environmental History. Ecological History Review, 1, 145-146. https://doi.org/10.17104/9783406698231-145

[37] Dearden, N. (2015) Paris Agreement: 1.5 Degrees in the Text, but 3 Degrees in Reality.

http://oneworld.org/2015/12/12/too-weak-too-late-says-climate-justice-campaigners/

[38] Shamsuddoha, M., Iqbal, S., Datta, A. and Rahman, M.M. (2018) Troubled Journey towards Climate Justice: Tackling Manifest Climate Injustice in the Loss and Damage Negotiations. Policy Paper. Center for Participatory Research and Development (CPRD), Dhaka.

[39] Siegele, L. (2012) Loss and Damage from the Adverse Effects of Climate Change-A SIDS View on Africa. https://germanwatch.org/en/4747

[40] Verheyen, R. and Roderick, P. (2008) Beyond Adaptation: The Legal Duty to Pay Compensation for Climate Change Damage. WWF-UK Climate Change Program Discussion Paper.

http://assets.wwf.org.uk/downloads/beyond_adaptation_lowres.pdf

[41] Warner, K., van der Geest, K. and Kreft, S. (2013) Pushed to the Limit: Evidence of Climate Change-Related Loss and Damage When People Face Constraints and Limits to Adaptation. United Nations University Institute for Environment and Human Security, Bonn.

[42] Richards, J.A. and Boom, K. (2014) Carbon Majors Funding Loss and Damage. Discussion Paper, Vol. 39, Heinrich Böll Stiftung Publication Series Ecology, Berlin.

[43] Doelle, M. (2015) Loss and Damage in the UN Climate Regime: Prospects for Paris. https://doi.org/10.2139/ssrn.2567368

[44] Joyce, D. (2015) No Jobs on a Dead Planet (Updated). http://www.ictu.ie/blog/2015/12/11/no-jobs-on-a-dead-planet-updated

[45] International Labour Organization (2015) ILO Welcomes New Climate Change Agreement Committing Nations to a Just Transition and the Creation of Decent Work.

http://www.ilo.org/global/topics/green-jobs/news/WCMS_436322/lang--en/index.h $\underline{\mathrm{tm}}$

[46] Anderson, K. (2015) Duality in Climate Science. Nature Geoscience, 8, 898-900. https://doi.org/10.1038/ngeo2559

[47] Fotabong, E.L. (2016) The Paris Agreement and African Agriculture. Great Insights Magazine, Volume 5, Issue 3.

https://ecdpm.org/great-insights/from-climate-commitments-to-action/paris-agree ment-african-agriculture

[48] Kenfack, C.E. (2015) Changements climatiques et droits humains fondamentaux: Vers une climatopolitique anthropocentrée. In: Mahktar Kante, A., Ed., Environnement, changement climatique et sécurité alimentaire en Afrique de POuest et du Centre: Compréhension des enjeux et pistes pour Pavenir, CODERIA, Dakar, 37-64.

[49] Kenfack, C.E. (2016) Vulnérabilité humaine et enjeux climatiques internationaux: De la climatopolitique stratégique aux droits de l'homme. Connaissances et Savoirs. Saint Denis.

[50] UNFCCC (1992) United Nations Framework Convention on Climate Change. http://unfccc.int/files/essential_background/background_publications_htmlpdf/app 
lication/pdf/conveng.pdf

[51] United Nations Conference on the Human Environment (1972) Declaration on the Human Environment.

https://wedocs.unep.org/bitstream/handle/20.500.11822/29567/ELGP1StockD.pdf?s equence $=1$ \&is Allowed $=\mathrm{y}$

[52] Gigounas, G., Gunst, A. and Webb, S. (2015) The UNFCCC Paris Agreement: Impressions from the Negotiating Table for the Energy Sector and 10 Key Points about What Comes Next.

https://www.dlapiper.com/en/us/insights/publications/2015/12/the-unfccc-paris-ag reement

[53] Buxton, N. (2016) COP 21 Charades: Spin, Lies and Real Hope in Paris. Globalizations, 13, 934-937. https://doi.org/10.1080/14747731.2016.1161936

[54] UNFCCC (1998) Kyoto Protocol to the United Nations Framework Convention on Climate Change. http://unfccc.int/resource/docs/convkp/kpeng.pdf

[55] Thunberg, G. (2019) If World Leaders Choose to Fail Us, My Generation Will Never Forgive Them. The Guardian, 23 September 2019.

https://www.theguardian.com/commentisfree/2019/sep/23/world-leaders-generatio n-climate-breakdown-greta-thunberg 